\title{
UM MODELO EVOLUTIVO PARA O PROCESSO DE GERAÇÃO E SELEÇÃO DE ALTERNATIVAS EM DESIGN
}

Fábio Gonçalves Teixeira

Universidade Federal do Rio Grande do Sul

fabiogt@ufrgs.br

Resumo: O processo de geração e seleção de alternativas da etapa de projeto conceitual do processo de design constitui um dos principais desafios de um projeto. O número possível de combinações entre funções e princípios funcionais pode atingir a casa dos milhões, o que inviabiliza uma busca exaustiva pelas melhores ou mais promissoras combinações. Diante disso, este trabalho propõe o uso de algoritmos genéticos (AG) para guiar o processo de geração de alternativas. $O$ trabalho apresenta uma proposta de framework para implementar o uso de AG, além de apresentar as principais características que tornam praticamente natural esta abordagem no processo de Design.

Palavras-chave: Algoritmos Genéticos, Geração de Alternativas, Seleção de Alternativas, Processo de Design.

\begin{abstract}
The conceptual design step is the most complex of the design process and brings great challenges to designers. The number of possible concepts from combination of functional principles can reach millions. This could derail an exhaustive search for the best possible concepts. So, this work proposes an evolutionary approach to that problem. The result is a framework based on a Genetic Algorithm (GA) that combines the specific properties of the design process with the core of $G A$, improving this process as a natural evolution.
\end{abstract}

Keywords: Genetic Algorithm, Concept Generation, Concept Selection, Design Process. 


\section{INTRODUÇÃO}

O processo de projeto é uma atividade complexa que pode ser dividida nas seguintes etapas principais: Projeto Informacional, Projeto Conceitual, Projeto Detalhado. O Projeto Informacional corresponde à etapa de coleta de informações envolvendo usuários e stakeholders, de forma conhecer em profundidade todos os fatores que se relacionam ao problema de projeto em questão. Ao final desta etapa, o problema de projeto está muito bem definido através dos requisitos de projeto (BACK et al., 2008).

O Projeto Conceitual é a etapa mais criativa do projeto, pois corresponde à etapa de geração e de seleção de alternativas de projeto. Este processo é orientado pelos requisitos de projeto, resultados da etapa do Projeto Informacional. Técnicas criativas são utilizadas para buscar soluções para os diversos problemas que se apresentam na busca do atendimento dos requisitos (ULRICH E EPPINGER, 2011).

A etapa do Projeto Conceitual apresenta diversos desafios, entre eles estão: definir a uma estrutura funcional para produto de forma a atender os requisitos de projeto; estabelecer princípios de solução para as diversas funções do produto; estabelecer combinações dos princípios de forma a gerar soluções (conceitos de projeto); selecionar as soluções que atendam aos requisitos e as especificações do projeto.

O principal desafio nesta etapa é definir uma forma de combinar os princípios de solução de forma a gerar soluções viáveis, uma vez que, mesmo em produtos de relativa baixa complexidade funcional, podem existir milhares ou até milhões de combinações possíveis. Isto torna o processo de geração de alternativas extremamente complexo, pois é humanamente impossível criar e avaliar todas estas combinações sem o auxílio de algum método ou algoritmo automatize determinadas tarefas em busca das melhores combinações frente aos requisitos de projeto.

Uma forma de trabalhar com este tipo de problema é fazer o uso de algoritmos genéticos, os quais são capazes de manipular um grande número de soluções através de processos que simulam a evolução e a seleção natural dos seres vivos (GOLDBERG, 1989).

Este trabalho apresenta uma proposta de framework para a utilização dos algoritmos genéticos para orientar o processo de geração e de seleção de alternativas na etapa de Projeto Conceitual no Design.

\section{DESENVOLVIMENTO DO FRAMEWORK PARA GERAÇÃO E SELEÇÃO DE ALTERNATIVAS}

Nesta etapa, são apresentados os principais passos de desenvolvimento da pesquisa. Na primeira etapa, é feita uma análise dos dados obtidos durante a revisão bibliográfica, de forma relacioná-los para estruturar um framework inicial da proposta de metodologia para a geração e seleção de alternativas.

\subsection{Algoritmos Genéticos}

Um Algoritmo Genético (AG) é um tipo de algoritmo evolutivo que utiliza a analogia dos processos genéticos dos seres vivos (GOLDBERG, 1989), como reprodução e mutação, e do processo de evolução das espécies, proposto por Darwin (1876), para a solução de problemas onde há muitas variáveis e um grande universo de soluções. Os AGs são utilizados na solução de problemas complexos em diversas áreas do 
conhecimento, incluindo computação, medicina, biologia e para a otimização de projetos em Engenharia.

Os AGs consideram uma população de indivíduos, onde cada um seria uma possível solução para o problema em questão. Cada indivíduo possui um código genético, o cromossomo, que define as principais características do indivíduo para resolver o problema. O cromossomo é composto de uma combinação de genes, os quais correspondem às expressões de características específicas. Os indivíduos podem se reproduzir pelo cruzamento de códigos genéticos de dois indivíduos. Um AG possui a seguinte dinâmica básica (KUREICHIK ET AL., 2009):

1. Uma função de aptidão (Fitness) é estabelecida;

2. Uma população inicial é criada com características aleatórias, como uma primeira aproximação, com indivíduos que, na totalidade possuam todos os genes disponíveis;

3. Os indivíduos são avaliados pelo Fitness e aqueles mais viáveis são selecionados (seleção natural);

4. Se os indivíduos selecionados atendem ao critério de parada, o processo para e vai para 7;

5. Os indivíduos selecionados se reproduzem, gerando uma nova população. Neste processo de reprodução, é adicionado um processo de mutação nos genes de forma aleatória;

6. Retorna ao passo 3;

7. O processo se encerra com uma população de indivíduos mais aptos segundo a função Fitness.

A estrutura dos AGs possui estreita relação conceitual com o processo de geração e seleção de alternativas. Muitas de suas características são, praticamente, equivalentes, como pode ser observado no Quadro 1, a seguir, que não deixa dúvidas sobre as grandes similaridades entre os dois processos.

Quadro 1 - Similaridades entre o processo de geração e seleção de alternativas de projeto e os AGs.

\begin{tabular}{|c|c|}
\hline $\begin{array}{r}\text { Geração e Seleção de } \\
\text { Alternativas }\end{array}$ & Algoritmos Genéticos \\
\hline Técnicas criativas & Mutação \\
\hline Estrutura Funcional & Cromossomo \\
\hline Princípios de Solução & Genes \\
\hline Matriz Morfológica & Cruzamento \\
\hline Matrizes de avaliação & Fitness \\
\hline Realimentação & Gerações sucessivas \\
\hline
\end{tabular}

Apesar desta similaridade, poucos trabalhos têm utilizado os AGs no processo de Design de novos produtos. Um exemplo, que trabalha apenas aspectos formais do produto, é o trabalho de Bezerra (1996), o qual estabelece algumas bases para o uso 
dos AGs na etapa de criação de formas para o produto. Outro exemplo é o trabalho de Stanković (2006), o qual trabalha mais com a questão funcional, mas não faz a relação entre as etapas do processo de projeto e as etapas dos AGs.

\subsection{Algoritmos Genéticos e os Processo de Geração e Seleção de Alternativas}

Os processos de geração e seleção de alternativas não podem ser tomados como etapas distintas e estanques. A forma mais adequada é considerar estas duas etapas como um processo integrado onde na geração prevalece o pensamento divergente e na seleção prevalece o pensamento convergente. Trata-se, portanto, de um processo cíclico com múltiplas etapas de geração e seleção até se chegar a um conceito final, o que indica a convergência deste processo.

Este processo poderia ser modelado através de um Algoritmo Genético - AG (GOLDBERG, 1989), onde a cada ciclo os conceitos gerados constituem uma geração da população. A aplicação de algoritmos genéticos no projeto de produtos é uma tendência na busca pela otimização dos projetos.

As características dos AG podem ser relacionadas diretamente aos processos de geração e seleção de alternativas. É possível utilizar a árvore funcional de um produto para configurar a estrutura do seu cromossomo. Os princípios de solução de cada função podem ser considerados como o conjunto de genes disponíveis. Assim, é possível construir um AG para o projeto de produto, onde o Fitness seria definido pelo conjunto de requisitos de projeto. Ao final do processo, restaria uma população de indivíduos que seriam aqueles mais aptos, ao final do processo evolutivo, para atender ao conjunto de requisitos de projeto.

Normalmente, os algoritmos genéticos são utilizados na solução de problemas das mais diversas áreas, como Engenharia, Ciências da Computação e Robótica. No entanto, embora pareça uma evolução lógica dos processos de geração de alternativas, ainda não foi utilizada no campo de Design com este fim. Desta forma, foi definido nesta pesquisa que a metodologia a ser desenvolvida para geração e seleção de alternativas teria como base a estrutura funcional de um AG.

O framework baseado nos AG para a geração e seleção de alternativas de projeto deve compatibilizar as principais características dos dois processos. Assim, é preciso definir como será o processo de avaliação (a função Fitness), o cromossomo e os genes frente aos parâmetros do processo de projeto do produto.

\subsection{Cromossomo e Análise funcional}

Em um AG, cromossomo é a expressão da lei de combinação dos genes. Assim, cada gene ocupa uma posição específica do cromossomo. Neste trabalho, foi considerado que a estrutura funcional irá orientar a formação do cromossomo do produto. Assim, ao ser feita a análise funcional, está sendo definida a estrutura genética do produto. 


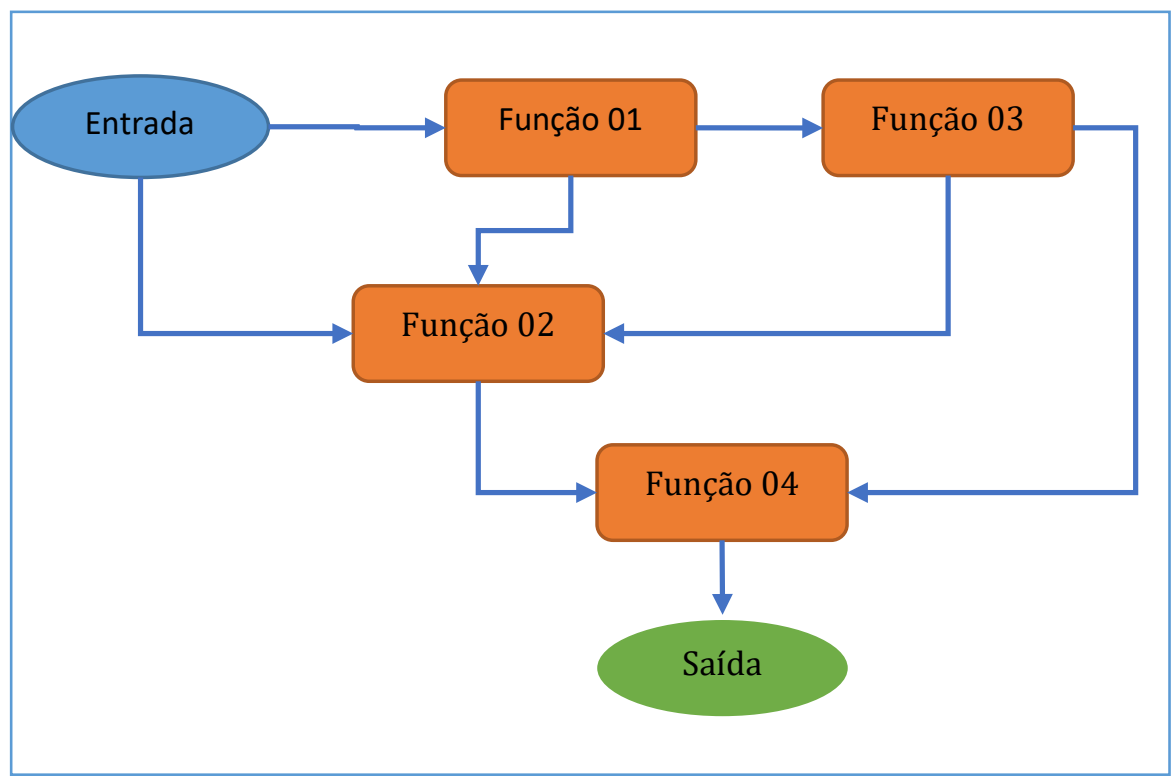

Figura 1 - Esquema de estrutura funcional de um produto.

A estrutura funcional é formada de todas as funções elementares do produto e as suas relações. Quando é utilizada a técnica da matriz morfológica, são priorizados os princípios de solução que possuem compatibilidade entre si. No entanto, esta compatibilidade não se constitui, necessariamente, em uma situação de sim ou não. Podem haver graus de compatibilidade variáveis entre determinados princípios de solução. Foi definido que o grau de compatibilidade $(\eta)$ será definido por um valor de 0 a 5. Este valor tem aplicação na definição do Fitness.

A definição do cromossomo é orientada pela estrutura funcional levando em conta as funções e suas relações. Figura 2 apresenta um esquema de um cromossomo de um produto segundo esta proposta. Os genes são dispostos em uma matriz quadrada cuja dimensão é igual ao número de genes que constituem um cromossomo. Os genes são dispostos na primeira coluna e na primeira linha. Assim, no cruzamento das linhas colunas são colocados os fatores de compatibilidade entre todos os genes do indivíduo. Por exemplo, o fator $\boldsymbol{\eta}_{13}$ corresponde à compatibilidade entre $\mathbf{G}_{1}$ e $\mathbf{G}_{3}$. Esta matriz, denominada de Matriz de Compatibilidade do Cromossomo (MCC), permite mapear a configuração geral do produto em seu cromossomo.

\begin{tabular}{|c|c|c|c|c|c|}
\hline Função & Genes & $\mathbf{G}_{1}$ & $\mathbf{G}_{2}$ & $\mathbf{G}_{3}$ & $\mathbf{G}_{4}$ \\
\hline 1 & $\mathbf{G}_{1}$ & - & $\eta_{12}$ & $\eta_{13}$ & $\eta_{14}$ \\
\hline 2 & $\mathbf{G}_{2}$ & $\eta_{21}$ & - & $\eta_{23}$ & $\eta_{24}$ \\
\hline 3 & $\mathbf{G}_{3}$ & $\eta_{31}$ & $\eta_{32}$ & - & $\eta_{34}$ \\
\hline & $\mathbf{G}_{4}$ & $\eta_{41}$ & $\eta_{42}$ & $\eta_{43}$ & - \\
\hline
\end{tabular}

Figura 2 - Matriz de Compatibilidade do Cromossomo (MCC) que contempla o fator de compatibilidade entre os genes constituintes do genoma. 


\subsection{Fitness e Requisitos de projeto}

A função de avalição de um indivíduo para verificar se o mesmo está conforme em relação à solução de um problema é chamada de Fitness. Num processo sistemático de desenvolvimento de produto, as alternativas de projeto devem ser comparadas com os requisitos de projeto para verificara viabilidade destas alternativas.

Assim, a função Fitness de um AG para a geração e seleção de alternativas de projeto deve utilizar os requisitos de projeto como base. Neste trabalho, foi determinado que o Fitness seria o somatório das notas de cada gene em cada requisito $\left(N G_{i, k}\right)$ multiplicadas pelos pesos de prioridade $\left(\rho_{i}\right)$ definidos no QFD, na etapa de projeto conceitual, e também pelo fator de compatibilidade de cada gene $\left(\eta_{i}\right)$. Assim, a função Fitness pode ser expressa pela seguinte equação:

$$
\begin{gathered}
F=\sum_{k=1}^{l} \sum_{i=1}^{n} N G_{i, k} \cdot \rho_{k} \cdot \eta_{i} \\
\eta_{i}=\prod_{j=1}^{n} \eta_{i, j}
\end{gathered}
$$

A Eq. 01 permite quantificar o quanto cada indivíduo satisfaz os requisitos de projeto e, ainda, o grau de compatibilidade (Eq. 02) entre os componentes internos, o que pode ser avaliado como uma nota de viabilidade do indivíduo. Esta nota é comparada com uma nota de corte, a qual é recalculada em cada geração. Indivíduos com notas iguais ou superiores à nota de corte são mantidos para o processo de cruzamento (combinação) para obter a nova geração de indivíduos.

\subsection{Genes e Princípios de Solução}

Em um AG, os genes correspondem às características específicas do indivíduo. Neste trabalho, os genes correspondem aos princípios de solução (ROZENFELD ET AL., 2006) para as funções da estrutura funcional. Como cada função pode ter vários princípios de solução, o número de configuração de cada gene é variável. Assim, o gene $\mathbf{G}_{3}$ poderia assumir as configurações $\mathbf{G}_{31}, \mathbf{G}_{32}, \ldots, \mathbf{G}_{3 n}$. Desta forma, o número de combinações cresce vertiginosamente com o número de genes do genoma e com o número de variações de cada gene. Para ilustrar o significado disso, é possível analisar o exemplo da Figura 2. Se naquele cromossomo, que possui 4 genes, existissem 5 variações de cada gene, o número possível de combinações seria de incríveis 1.728.000. Este número evidencia a importância de constituir uma metodologia que seja capaz de tratar deste problema de forma a priorizar as combinações mais viáveis em detrimento daquelas com baixa probabilidade de viabilidade.

\subsection{População Inicial}

Nos AG, as populações iniciais são geradas de forma aleatória para serem avaliadas em uma segunda etapa. Em um ambiente computacional, é possível gerar um grande número de indivíduos e a maior consequência é o tempo de processamento. No ambiente analógico, uma população inicial muito grande gera uma 
grande quantidade de trabalho, pois é necessário realizar as avaliações de muitos indivíduos de forma não automatizada.

Portanto, para este trabalho, o processo de avaliação se inicia, de certa forma, na geração da população inicial. Esta geração apresenta fatores aleatórios, mas também fatores heurísticos de forma a permitir a geração de indivíduos com genes (componentes) bem avaliados frente aos requisitos de projeto. Desta forma, é necessário fazer esta avaliação previamente. Porém, esta é uma tarefa que proporciona aprendizado, pois é possível alimentar um banco de dados com requisitos de projeto e genes, relacionando os requisitos de projeto compatíveis com determinados genes e as notas de satisfação correspondentes. Assim, em usos futuros estes parâmetros já estariam configurados. E cada novo projeto pode alimentar este banco de dados, gerando um aprendizado constante com o processo, além do registro e da documentação.

O processo de geração da população inicial é iniciado com o ranqueamento dos genes a partir de suas notas frente aos requisitos de projeto. Aqueles mais bem classificados são utilizados para a criação da população inicial de forma que haja todos os genes classificados sejam utilizados. Isto garante que todos os genes com boa classificação estejam contemplados na população inicial.

\subsection{Cálculo do Fitness}

O cálculo do Fitness utiliza a Equação 1 com os dados da Equação 2 e da MCC (Figura 2). Este processo pode ser calculado manualmente ou pode ser parcialmente automatizado na medida em que o processo é refeito. 0 problema é que muitas das notas atribuídas aos genes para o cálculo do Fitness dependem de avaliações subjetivas, as quais são difíceis de serem modeladas computacionalmente.

Nesta etapa, é iniciada a prototipagem virtual e física com o objetivo de avaliar os indivíduos, os quais correspondem a conceitos, alternativas de projeto. Com os protótipos físicos e virtuais é possível avaliar e atribuir notas aos genes relativas aos requisitos de projeto e também analisar a compatibilidade entre determinados genes. Conforme o número de indivíduos (conceitos) da população, é facultado o início do processo de prototipagem. Eventualmente, este processo pode ser desencadeado somente após a população (número de alternativas de projeto) ser reduzida a um número de indivíduos inferior a um certo limite, o qual irá depender de fatores como os recursos materiais e humanos para realizar estes protótipos. Outra hipótese é variar o nível fidelidade dos protótipos na medida em que o processo avança. Assim, nas primeiras gerações, utilizam-se protótipos de baixa resolução e, nas gerações finais, utilizam-se protótipos de alta resolução.

\subsection{Ranqueamento e Seleção}

O ranqueamento dos conceitos de projeto em uma determinada geração é feito com base no Fitness de cada indivíduo. A seleção dos indivíduos mais aptos é feita considerando como nota de corte o Fitness médio da geração anterior. Assim, é garantido que cada geração seja descendente de pais que possuem Fitness acima da média de sua geração. Estes parâmetros podem ser alterados para cima ou para baixo conforme a conveniência de cada situação de projeto. 


\subsection{Cruzamento e Mutação}

Após o ranqueamento e a seleção dos conceitos com maior pontuação, estes são utilizados como genitores da nova geração de indivíduos. O cruzamento é feito agrupando os indivíduos em pares de forma aleatória e sem repetição. Cada cruzamento gera dois filhos, cada um com uma forma diferente de combinação de código genético.

Podem ser muitas as formas de combinação. Neste trabalho, optou-se pelo uso de um único padrão básico. As sequências genéticas dos cromossomos dos dois genitores são seccionadas no meio e os dois descendentes são gerados a partir da combinação das duas metades dos códigos genéticos dos dois genitores (Figura 3).

Em um certo percentual de indivíduos é inserida uma mutação durante o processo de cruzamento. Neste trabalho, a mutação se constitui na alteração aleatória de um dos genes de $5 \%$ da população total acumulada. 0 normal seria de até $5 \%$ da população de cada geração. No entanto, como o processo proposto aqui utiliza uma população reduzida, não haveria indivíduos suficientes em cada geração e, portanto, não haveria mutação. Assim, considerando a população acumulada, é garantido que haverá mutações, mas não em todas as gerações. Quando a população acumulada desde a última mutação atinge um número onde $5 \%$ seja maior ou igual a 1 indivíduo, a mutação é aplicada aleatoriamente em um indivíduo da população atual.

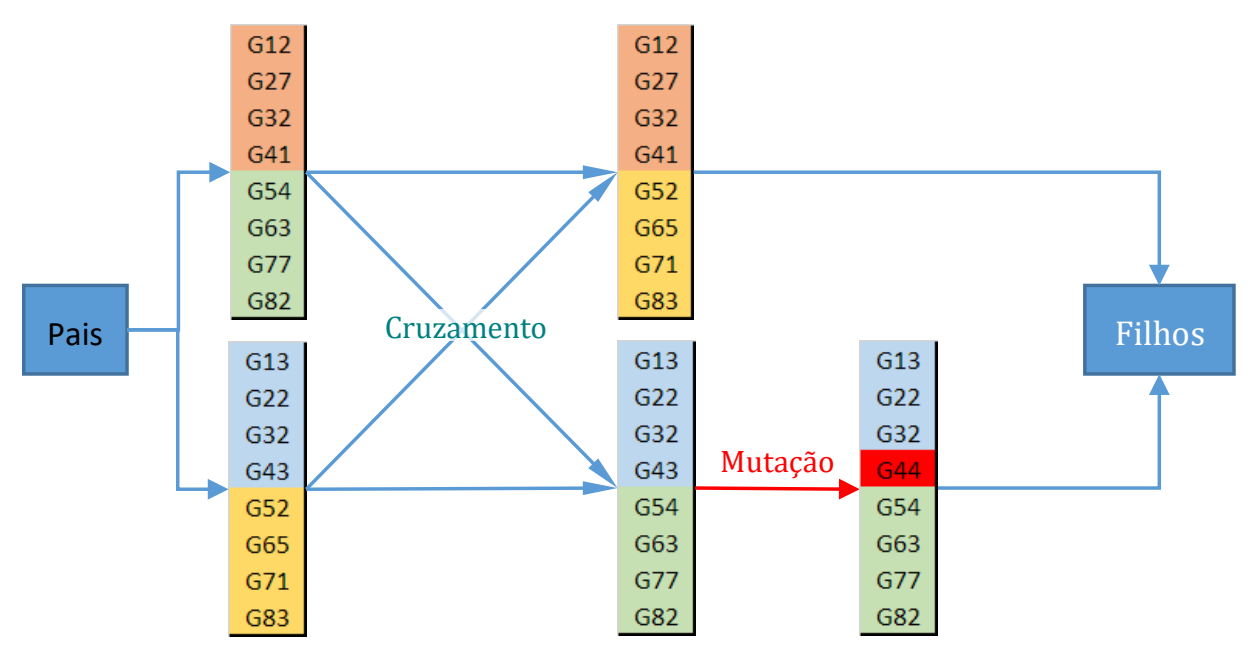

Figura 3 - Cruzamento de dois indivíduos: Esquema de combinação do código genético.

\subsection{Framework de Geração e Seleção de Alternativas Baseado nos AG}

A abordagem genética, que foi levantada, normalmente é aplicada na solução de problemas com um grande universo de possibilidades de solução, que é exatamente o caso do processo de Design. Este tipo de técnica utiliza, normalmente, plataformas computacionais, de forma a automatizar totalmente o processo evolutivo.

Neste trabalho, os AGs são base que ordena o processo de geração e seleção de alternativas. No entanto, a proposta é a utilização dos princípios dos AGs com o uso de plataforma computacional somente em determinadas etapas do processo, com 0 objetivo de agilizar e também de documentar o processo. A ideia é fornecer as bases para que, no futuro, seja possível implementar um processo de geração e seleção de alternativas totalmente automatizado, fundamentado na experiência de aplicação dos AGs iniciadas nesta pesquisa. 
A Figura 4 apresenta o fluxograma do framework para a geração e seleção de alternativas de projeto proposto que irá controlar o processo de geração e seleção de alternativas através de um algoritmo genético. Cada um dos componentes deste fluxograma contém uma série de ações intrínsecas as quais foram descritas nos tópicos anteriores.

O processo começa com os requisitos de projeto do produto. A partir destes, é definida a estrutura funcional do produto, a partir da qual será definido o cromossomo do produto e mapeados os princípios de solução, que constituirão o conjunto de genes possíveis para povoar o cromossomo. A variação dos genes em cada posição do cromossomo gera indivíduos distintos. Assim, uma população inicial é gerada utilizando variações genéticas aleatórias na MCC que atendam faixas de Fitness aceitáveis, considerando que o Fitness depende exclusivamente dos requisitos do projeto. Após a definição da população inicial, o algoritmo genético é iniciado com um processo iterativo, onde a população atual tem os seus indivíduos ranqueados. Os indivíduos mais aptos em cada geração são cruzados entre si para gerar uma nova população. As sucessivas gerações são avaliadas até que se atinja o critério de parada, que pode ser relativo à aptidão (Fitness) de um indivíduo ou à média da população. Após à parada, os indivíduos da última geração são ranqueados para a seleção final, a qual pode ser realizada de forma automática, por algum algoritmo de seleção, ou pela equipe de projeto seguindo critérios mais subjetivos, considerando a experiência da equipe e as estratégias da empresa. 


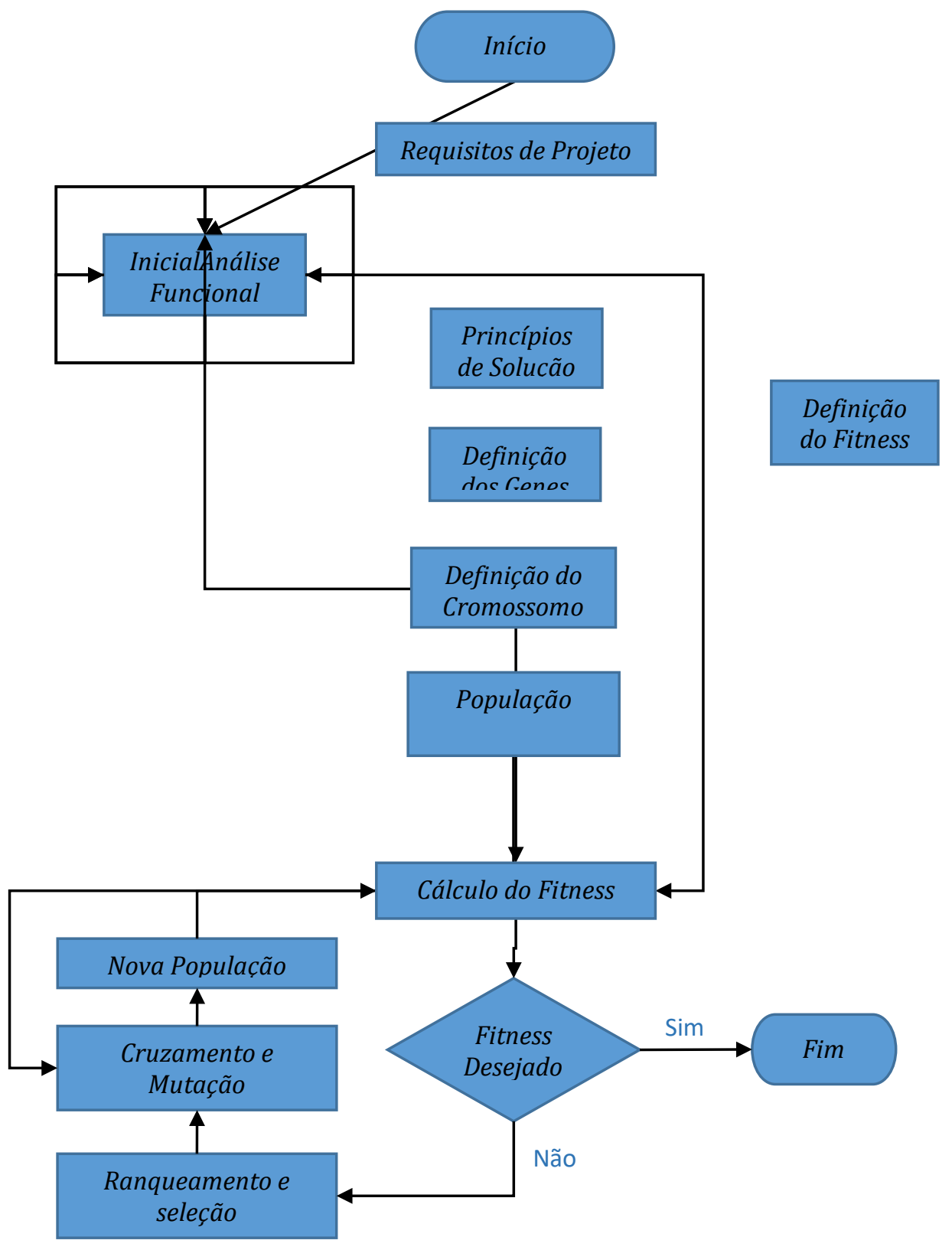

Figura 4 - Fluxograma do framework para a geração e seleção de alternativas de projeto.

\section{CONSIDERAÇÕES FINAIS}

Neste trabalho, foi proposto um Framework onde é possível utilizar ferramentas conhecidas do processo de geração e seleção de alternativas, do processo de design, seguindo os passos de um AG. A análise funcional do produto gera uma estrutura funcional que é a base para o código genético do produto. Uma matriz morfológica é utilizada para estabelecer princípios de solução de para as funções elementares da estrutura funcional. Estes princípios de solução correspondem aos genes que irão preencher o cromossomo e dar características ao produto. Conforme os genes (princípios de solução) elencados, são gerados indivíduos distintos. Assim, o processo inicial com uma população inicial, definida por critérios de convergência, e seus membros se reproduzem entre si, através de cruzamento genético, criando uma nova geração de indivíduos. Neste caso, cada geração corresponde a um conjunto de alternativas de projeto de um produto. Cada vez que uma nova população é gerada, 
todos os indivíduos são avaliados pelo Fitness, que mede o grau de viabilidade de cada indivíduo em relação aos requisitos de projeto. Os indivíduos com baixa viabilidade são eliminados e os restantes são escolhidos como pais da geração seguinte. O processo termina quando é atingido um Fitness considerado adequado como solução de projeto.

Além da contribuição da metodologia desenvolvida, expressa no Framework proposto, esta pesquisa estabelece uma base de conhecimento para o uso dos AGs no processo de design e define parâmetros para a sua aplicação de uma forma ampla. Esta base de conhecimento pode ser utilizada para desenvolver um sistema de computacional para o processo de geração e seleção de alternativas de forma totalmente automatizada e generativa. Isto depende da modelagem e avaliação paramétrica dos conceitos através de protótipos virtuais que poderiam ter seus Fitness calculados automaticamente

A aplicabilidade deste Framework vai dos aspectos funcionais até os aspectos formais do produto, uma vez que toda a estrutura formal-funcional de um produto possa ser codificada em um cromossomo. A partir de uma análise funcional que inclua funções práticas e estético-formais, seria possível utilizar esta abordagem para qualquer tipo de produto. Isto traz implicações importantes no projeto, pois, na maioria dos casos, os designers geram uma quantidade de alternativas que é apenas uma fração das reais possibilidades considerando todas as combinações possíveis, que podem chegar a milhões. Utilizando sistemas computacionais baseados em algoritmos genéticos para a geração e seleção de alternativas de projeto, seria possível verificar um universo muito maior de possibilidades, estendendo a capacidade humana de gerar e analisar alternativas de projeto e, assim, criar produtos que melhor atendam aos usuários.

\section{REFERÊNCIAS}

BACK, N.; OGLIARI, A.; DIAS, A. e SILVA, J. C. Projeto Integrado de Produtos. Manole, Barueri, SP, 2008.

BEZERRA, C. D. Evolução interativa e a aplicação de algoritmos genéticos no design de produtos. 1996. Dissertação (Mestrado) - Universidade Federal de Santa Catarina, Curso de Pós-Graduação em Engenharia de Produção.

GOLDBERG, D. Genetic Algorithms in Search, Optimization and Machine Learning. Reading, MA: Addison-Wesley Professional, 1989.

KUREICHIK, V.M., MALIOUKOV, S.P., KUREICHIK, V.V., MALIOUKOV, A.S. Genetic Algorithms for Applied CAD Problems. Springer-Verlag, Berlin-Heidelberg, 2009.

ROZENFELD, H.; FORCELLINI, F.A.; AMARAL, D.C.; TOLEDO, J.C.; SILVA, S.L.; ALLIPRANDINI, D.H.; SCALICE, R.K. Gestão de Desenvolvimento de Produtos: uma referência para a melhoria do processo. São Paulo: Saraiva, 2006.

STANKOVIĆ, T.; STOŠIĆ, M. e MARJANOVIĆ, D. Evolutionary algorithms in design. In: International Design Conference, 9., 2006, Dubrovnik. Proceedings of... Dubrovnik, 2006, p385-392.

ULRICH, K. e EPPINGER, S. Product Design and Development. McGraw-Hill, New York, 2008. 